\title{
Recognising the Gastrointestinal Manifestation of Pediatric Coronavirus Disease 2019
}

\author{
Rishi Bolia ${ }^{1}$ (D) $\cdot$ Raksha Ranjan ${ }^{1} \cdot$ Nowneet Kumar Bhat ${ }^{1}$ \\ Received: 25 June 2020 / Accepted: 21 August 2020 / Published online: 26 August 2020 \\ (C) Dr. K C Chaudhuri Foundation 2020
}

To the Editor: Ever since the COVID-19 pandemic has hit the world the landscape of its clinical manifestations has been changing and its gastrointestinal (GI) features are now being recognised more frequently $[1,2]$.

Similar to the respiratory tract, SARS-CoV-2 binds to GI tract cells via the ACE- 2 and TMPRSS2 cell receptors in the intestine causing release of cytokines. Fecal shedding of the virus has been demonstrated, which may continue even after nasopharyngeal swabs become negative.

Two children (9 y/Male, $15 \mathrm{y} / \mathrm{Male})$ were admitted to our hospital with profuse nausea and vomiting for $\sim 2 \mathrm{~d}$. The vomiting was non-projectile, non-bilious and had occurred 7-8 times. They had no respiratory symptoms. Complete blood count, liver function tests, stool examination, serum lipase, ultrasound abdomen and chest X-ray were normal in both. Both were found to have a positive nasopharyngeal SARS-Cov-2 RT-PCR and were given only symptomatic management (anti-emetics, intravenous fluids) with which the symptoms recovered uneventfully.

GI symptoms may be the sole symptoms of COVID$19(\sim 10 \%)$, may precede respiratory symptoms or may manifest later during the disease course [2]. In a pooled analysis, GI manifestations were reported in $12 \%$ children with COVID-19 [1]. Apart from nausea/vomiting (10-10.6\%) as seen in our patients, symptoms include -abdominal pain (4$5.8 \%)$, diarrhea $(9-12.7 \%)$ and anorexia/feeding difficulties (23\%) [3]. Recently, GI symptoms have come to the fore with the recognition of multisystem inflammatory syndrome (MIS-C), a manifestation of COVID-19 with systemic hyperinflammation and multi-organ failure. In the largest series $(n-$ $=44)$ of MIS-C, $84.1 \%$ had GI symptoms [abdominal

Rishi Bolia

rishibolia@yahoo.co.in

1 Division of Pediatric Gastroenterology, Department of Pediatrics, All India Institute of Medical Sciences, Rishikesh, Uttar Pradesh, India pain (75\%), vomiting (56\%), diarrhea (40\%)] [4]. These symptoms mimic viral/bacterial gastroenteritis or even inflammatory bowel disease. Markedly elevated inflammatory markers and other symptoms like fever, rash and/or conjunctivitis should raise a suspicion of COVID-19. Interestingly, only $25 \%$ of these patients had severe respiratory symptoms. Another intriguing GI manifestation is a "surgical" abdomen clinically mimicking appendicitis. Imaging showed features of terminal ileitis, ileo-colitis and/or mesenteric lymphadenitis, all patients improving with conservative management [5]. The recognition of GI manifestations is important in children as children infected with coronaviruses have GI symptoms more often compared with adults $[2,6]$.

To conclude, we would like to highlight the spectrum of GI manifestations of pediatric COVID-19 reported in literature which may range from mild non-specific symptoms as seen in our patients to severe symptoms mimicking a "surgical" abdomen, which may occur even in the absence of respiratory symptoms. It is important for pediatricians to be aware of these clinical presentations and maintain a high index of suspicion for COVID-19, especially in those who have been exposed to a COVID-19 patient.

Acknowledgements We would like to thank Dr. Deepjyoti Kalita and the microbiology team at our institute for carrying out the SARS-Cov-2 RTPCR.

\section{Compliance with Ethical Standards}

Conflict of Interest None.

\section{References}

1. Chang TH, Wu JL, Chang LY. Clinical characteristics and diagnostic challenges of pediatric COVID-19: a systematic review and metaanalysis. J Formos Med Assoc. 2020;119:982-9.

2. Tian Y, Rong L, Nian W, He Y. Review article: gastrointestinal features in COVID-19 and the possibility of faecal transmission. Aliment Pharmacol Ther. 2020;51:843-51. 
3. Parri N, Lenge M, Buonsenso D; Coronavirus Infection in Pediatric Emergency Departments (CONFIDENCE) Research Group. Children with Covid-19 in Pediatric Emergency Departments in Italy. N Engl J Med. 2020. https://doi.org/10.1056/NEJMc2007617.

4. Miller J, Cantor A, Zachariah P, Ahn D, Martinez M, Margolis K. Gastrointestinal symptoms as a major presentation component of a novel multisystem inflammatory syndrome in children (MIS-C) that is related to COVID-19: a single center experience of 44 cases. Gastroenterology. 2020. https://doi.org/10.1053/j.gastro.2020.05. 079. [Epub ahead of print].

5. Tullie L, Ford K, Bisharat M, et al. Gastrointestinal features in children with COVID-19: an observation of varied presentation in eight children. Lancet Child Adolesc Health. 2020;4:e19-20. https://doi. org/10.1016/S2352-4642(20)30165-6.

6. Zimmermann P, Curtis N. Coronavirus infections in children including COVID-19: an overview of the epidemiology, clinical features, diagnosis, treatment and prevention options in children. Pediatr Infect Dis J. 2020;39:355-68.

Publisher's Note Springer Nature remains neutral with regard to jurisdictional claims in published maps and institutional affiliations. 